Trinity University

Digital Commons@ Trinity

English Faculty Research

English Department

$10-2006$

\title{
Stanley Cavell and Criticizing the University from Within
}

Michael Fischer

TrinityUniversity, mfischer@trinity.edu

Follow this and additional works at: https://digitalcommons.trinity.edu/eng_faculty

Part of the English Language and Literature Commons

\section{Repository Citation}

Fischer, M. (2006). Stanley Cavell and criticizing the university from within. Philosophy \& Literature, 30(2), 471-483. doi: 10.1353/ phl.2006.0028

This Article is brought to you for free and open access by the English Department at Digital Commons @ Trinity. It has been accepted for inclusion in English Faculty Research by an authorized administrator of Digital Commons@ Trinity. For more information, please contact jcostanz@trinity.edu. 


\section{PROJECT MUSE}

\section{Stanley Cavell and Criticizing the University from Within}

Michael Fischer

Philosophy and Literature, Volume 30, Number 2, October 2006, pp.

471-483 (Article)

Published by Johns Hopkins University Press

DOI: 10.1353/phl.2006.0028

$\Rightarrow$ For additional information about this article

http://muse.jhu.edu/journals/phl/summary/v030/30.2fischer.html 


\section{STANLEY CAVELL AND CRITICIZING THE UNIVERSITY FROM WITHIN}

Canley Cavell has spoken often of his "lifelong quarrel with the profession of philosophy" but he has said less about the university as a whole and its pressures on all academic disciplines, philosophy included. ' In Cavell's work, "academic" or "professional" philosophy takes shape in an institutional context he has not yet fully analyzed. I want here to extrapolate from Cavell's work a critical, yet sympathetic, response to the university that I think is especially needed today, when the rise of the so-called corporate university is intensifying some of the professional pressures that Cavell resists.

Cavell's discomfort with academic philosophy stems in part from what he regards as its narrowness, specifically, its marginalization of Ludwig Wittgenstein and other philosophers, not to mention Henry David Thoreau and Ralph Waldo Emerson, the comedies of remarriage, and other work that Cavell cares about. In his view, the professional marginalization of these writers partly results from their exemplifying what can seem to be a vague moral seriousness, even at times a prophetic urgency, that calls for something akin to conversion rather than issuing in specific conclusions or reforms. According to Cavell, academic philosophy, by contrast, subsumes moral concerns under ethics, a separate field in which the "point of conversation is getting the other to agree to, or to do, something." 2

Although Cavell does not systematically analyze the institutional pressures on academic philosophy, he does drop some hints. As befitting a subject seeking legitimacy in the university, academic philosophy has aligned itself with teachable subjects such as science, as opposed to more elusive pursuits such as painting and creative writing, which 
have been less at home in the university and where the necessity of university instruction may be less clear and the line between success and failure harder to draw. ${ }^{3}$ What can be taught in academic philosophy is a method of analysis, mastery of which can be certified in students by professors and in professors by journals, promotion and tenure committees, and administrators. Subdividing philosophy into discrete fields such as ethics makes it even more manageable, or less susceptible to sweeping pronouncements that cannot be tested by experts. Finally, the interest in getting "the other to agree to, or to do, something" associates academic philosophy, or at least ethics, with measurable results and maybe even progress.

The rise of the so-called corporate university has exacerbated the emphasis on teachable expertise and definable outcomes that I have been describing. Take the largest private university in the United States-the University of Phoenix-as a model that some state and non-profit private universities may be emulating as they struggle to cut costs, meet external expectations, and work with reduced budgets. At the University of Phoenix, the interest in measurable results gets recast as learning outcomes that teachers enable students to reach as efficiently as possible. Specialization narrows these learning outcomes to sharply defined skills, such as writing business memos, which students can master and build on. Finally, the emphasis on method does not simply depersonalize instruction; it reduces the need for instructors. Each instructor is tasked with teaching as many students as possible, sometimes through distance learning, with class size reaching a limit only when the learning outcomes cannot be delivered. Lacking tenure, these instructors can be replaced, like interchangeable parts, when they wear out or their student customers become too dissatisfied with them. At another rapidly growing for-profit university, DeVry, students unhappy with their instructors are assured, in the words of a campus dean, that "weak links" will be "fixed" in a "total quality management" environment. ${ }^{4}$

Along similar lines, Lindsay Waters has recently explored how "the corporate makeover of the university" and "the commercialization of higher education" have affected academic publishing. ${ }^{5}$ Universities compete in an increasingly cutthroat marketplace and face an escalating insistence on results from state legislatures, federal agencies, accrediting associations, and boards. Capitulating to this "accountability culture" (EP, p. 20), bottom-line driven administrators have stepped up demands for faculty productivity, measured in quantitative terms by numbers of students taught, grants won, and, what most concerns Waters, books and 
articles published. These administrators have "outsourced" tenure and promotion decisions to journal editors and academic publishers, much like Ford buying batteries from Delcro (EP, p. 25). In Waters' polemic, everyone is implicated in the loss of "any transcendental element" ( $E P$, p. 11), any element of judgment or imagination, in the corporatist university: "greedy deans and provosts" (EP, p. 37); undiscriminating journal and university press editors who abandon standards "to keep the assembly-line moving" ( $E P$, p. 22$)$; librarians who fail to protect "book budgets from rapacious commercial presses who gouge them on journals" (EP, p. 37); and ambitious faculty members, "captains of academic industry" (EP, p. 67), who pursue star status instead of institutional change and who remain oblivious to the suffering of exploited adjuncts, like smug corporate CEOs insulated from their less well off employees (EP, p. 29).

I am not suggesting that academic philosophers are responsible for these tendencies or would endorse them. My point is that the remaking of universities along corporate lines has exacerbated pressures that have long impinged on disciplines seeking university legitimacy. Some of these pressures result from universities being institutions with limited resources that will always have to set priorities and justify what they do. There is nothing new or even necessarily objectionable about calls for accountability, productivity, and efficiency. Universities should be interested in containing costs, assessing the effectiveness of their programs, and thinking through their choices. What is new and objectionable is reducing the goals of universities to immediate, quantifiable results.

The question remains, however, what are those of us in universities to do about these corporatist tendencies besides vent, like Waters, or give in, like the DeVry dean? For some guidance, I want to return to Cavell's dissatisfaction with academic philosophy. Cavell does not categorically reject academic philosophy. Instead, he recognizes it as "the genuine present of the impulse and the history of philosophy, so far as that present takes its place in our (English-speaking) public intellectual life" (TS, p. 32). As a writer, he wants neither to bypass academic philosophers as an audience nor limit his writing to their models. He admits to a "career-long wish" for his work "to be answerable to professional philosophy." Cavell's accountability to professional philosophy has puzzled some of his readers, among them Richard Rorty, who detect in Cavell an institutional timidity at odds with the boldness of his preference for Thoreau and other writers. As Cavell paraphrases Rorty's concern, "to go on to worry whether certain of the texts I promote are philosophy 
or are something else (say literature) is unnecessary; or rather, it is something deans worry about." Cavell responds,

Would it have helped to add that what I care about in a work is what the work shows itself to be, to let happen, to care about, and that this is not something that can be known by how a dean, or anyone else, decides to classify texts and thereupon to invest in them? ${ }^{7}$

The works that interest Cavell show themselves to be steeped in philosophical issues (such as skepticism), committed to philosophical goals (such as liberation from false necessities), and capable of philosophical rigor in their thinking and writing. ${ }^{8}$ By calling these works "philosophical," Cavell is claiming that they reward a deep level of attentiveness and seriousness in our approach to them. Instead of giving up on academic philosophy, he wants these works to put pressure on it, and for him that means continuing to call them "philosophical" and persisting in writing "at once inside the profession of philosophy and outside" (PDAT, p. 193).

Potentially even more worrisome to a dean, Cavell has long wondered not just whether the writing that he most values belongs in philosophy or literature departments but whether it is teachable at all. The limits of instruction, the inability of teachers to guarantee the effectiveness of their teaching, is a major moment in all the writers that interest Cavell, expressed sometimes from the point of view of a student (for example, Emerson's remark in his "Divinity School Address" that "truly speaking, it is not instruction, but provocation, that I can receive from another soul" $)^{9}$ and sometimes from the point of a view of a teacher, as in Wittgenstein's Investigations \#217: "If I have exhausted the justifications I have reached bedrock, and my spade is turned. Then I am inclined to say: 'This is simply what I do'" (quoted in CHU, p. 70). In wanting their work to be taken up and continued voluntarily, in wishing to prevent understanding which is unaccompanied by profound inner change, in thus asking so much of their readers, including trust and an openness to uncertainty, self-doubt, and self-scrutiny, Emerson and Wittgenstein admit that the effectiveness of their teaching depends on the always unpredictable consent of their students or readers. ${ }^{10}$ Although this consent can be provoked, it cannot be forced, taken for granted, or reduced to routine without violating the autonomy that it depends on. In The Claim of Reason, after noting the lack of impact made by Wittgenstein and Austin on academic philosophical culture, Cavell adds, "I do not 
say that this is a bad thing"11_ that is, a thing that can be moralized or easily fixed. Later, in This New Yet Unapproachable America, after making a similar point about the "insufficient" reception of Wittgenstein by professional philosophy, Cavell says, "I am not interested in expressing or assessing blame for this situation, either of those who may neglect the spiritual fervor [of Wittgenstein] as philosophically impertinent or of those who may insist on the fervor impertinently" (NYUA, p. 30). It is an open question for Cavell "whether the soul's journey is any part of a university's business, hence to what extent, if it is an essential part of philosophy's business, philosophy is left out of the university," or should be (CHU, p. 32). In short, he is not sure "whether any sky remains a canopy for philosophy" (NYUA, p. 8).

Even as Cavell refuses to demonize academic philosophy or philosophers, he often expresses his gratitude to the universities that he has been associated with—to the intellectual community he enjoyed at Berkeley, to teachers like J. L. Austin, to colleagues and students, to the teaching fellows of a particular course (Cities of Words, a book, he says, "that was born in a classroom" [CW, p. 163] is dedicated to the teaching fellows in Moral Reasoning 34). In an early essay on film in the university, he asks, playfully paraphrasing Marx,

Isn't a university the place in our culture that enables us now to teach one thing today and learn another tomorrow, to hunt for time to write in the morning, fish for a free projector in the afternoon, try to raise money for projects in the evening, and after a seminar read criticism? To some this will not seem a Utopian set of activities, but in the meantime, and for those with a taste for this particular disunity, why not have it? ${ }^{12}$

As someone who has benefited from being in a university, he speaks with conflicting emotions of "gifted philosophical sensibilities deflected from pursuing their love of philosophy by their unwillingness or incapacity to face institutionalized disapproval" (NYUA, p. 6). Although he empathizes with their isolation, he never romanticizes it. He notes "how one grows weary of oneself with only oneself for conversation; and one gets cranky as well as hoarse .... But the worst is that isolation causes uncreativeness and parochialism more often than it makes for anything better" (PH, p. 273-74). At any rate, despite his ongoing doubts about whether as a university professor in a philosophy department he is in the right place, he writes The Claim of Reason as "the record of one who stayed" ( $C R$, p. xviii). 
I am interested here not in why Cavell has stayed but in what staying means. For one thing, staying, whether in academic philosophy or the university, means being fortunate enough to having gotten in. To borrow from Cavell's analysis of moral perfectionism, having gotten in puts Cavell among the advantaged in our society-not the most advantaged, to be sure, but not the least, either. In Cavell's case, or, I would argue, in the case of any tenured university professor (i.e., not just one with an endowed chair at Harvard), "advantaged" means working in an institution that permits a degree of autonomy, security, and critical thinking rarely found in other American workplaces.

For all their many benefits, however, universities are not perfect, the remaking of universities along corporate lines being only one example of ominous tendencies most of us would criticize. It would be easy to turn Cavell's dissatisfaction with academic philosophy into a wholesale indictment of a spineless profession that has curried institutional favor by excluding what it most ought to value (I can imagine Waters taking this path). It would also be easy to fault Cavell for not making this indictment-for seeming to set aside his grievances and ignoring the injustices, omissions, and shortsightedness of the university environment that supports him. From this point of view, Cavell's decision to stay, his consent to remaining a member of the academic profession, compromises him and nullifies the value of his work for those who are not so privileged or content.

Cavell not only understands the alienation and anger that fuel this critique; he shares them. One of his most frequently quoted comments is from Emerson's "Self-Reliance," "Every word they say chagrins us and we know not where to begin to set them right" (quoted in NYUA, p. 69 ), which speaks of an intellectual isolation so deep that it could lead to despair and fuel dreams of escape. In Emerson, it does not, partly because he realizes that some measure of isolation-he calls it "poverty and solitude"-attends all serious philosophical work, wherever one undertakes it. Eschewing conformity, the scholar, in Emerson's words, "takes the cross of making his own [road]" and with it "the self-accusation, the faint heart, the frequent uncertainty and loss of time, which are the nettles and tangling vines in the way of the self-relying and self-directed; and the state of virtual hostility in which he seems to stand to society, and especially to educated society." ${ }^{13}$ Neither Emerson nor Cavell can imagine a society or even a relationship where these feelings will once and for all way give way to acceptance, recognition, and unconditional support. As Cavell puts it, some measure of misunderstanding and social 
rejection is "a characteristic fate of philosophy, at least in any somewhat novel form" (CW, p. 163).

Acknowledging the inevitability of rejection and neglect tempers our search for community and may incline us to concede, however begrudgingly, that the place we inhabit-in this case, the university-is good enough: maybe not perfect but better than any conceivable alternative, especially when we take into account, as Cavell does, the costs of more radical forms of isolation, such as bitterly leaving the academic profession or sadly not getting in. This acceptance of the university as the best place we can find (for now) is hardly a ringing endorsement and can lead to various strategies for adapting to an environment one cannot flee or change, a place where, in Cavell's words, our consent "can neither be given nor withdrawn” ( $C W$, p. 198). These adaptive responses include silent melancholy, quiet desperation, indifference, cynicism, aloofness, or adopting what Cavell calls, following Emerson, the "forced false smile of conformity" ( $C H U$, p. 28), pasted on to survive conversations that do not interest us and situations where we do not feel at home. All of these help us survive a world where we feel stuck, invisible, lost, powerless to make ourselves intelligible to others, let alone influence them, and uncomfortably aware that our privileges may be somehow bound up with the sufferings of others but not sure where our responsibilities lie or how we can carry them out.

For Cavell, inheriting the writing of Emerson, Wittgenstein, and others, going on with it in our own often dark time, means above all showing us how to withstand moral cynicism, or how to respond to the inevitable failures of our institutions-universities included-and our complicity with them, "otherwise than by excuse or withdrawal" (CHU, p. 18). I think a key move on his part is to shift our attention from persuading or defeating the scoundrels in our lives, which can seem futile, to releasing the good in ourselves and in others, as Austin did for him (Cavell says he owes Austin "whatever is owed the teacher who shows one a way to do relevantly and fruitfully the thing one had almost given up hope of doing"). ${ }^{14}$ As Cavell puts it, "a philosopher will naturally think that the other has to be argued out of his position, which is apt to seem hopeless. But suppose the issue is not to win an argument ... but to manifest for the other another way ... a shift in direction, as slight as a degree of the compass, but down the road making all the difference in the world" (CHU, p. 31). Cavell's ongoing quarrel with academic philosophy becomes what Emerson might call an aversive conversation with what, for all Cavell knows, may be an implacable 
force but a conversation which other individuals may pick up on and sustain because it represents a shift in direction they also are wishing to take. By continuing his conversation with academic philosophy without any guarantee of institutional impact, by exemplifying another way of doing philosophy, Cavell is acting on the hope that some individuals somewhere will find in his words their own repressed thoughts returned to them and be encouraged to continue. The force of his words lies in their power not to compel agreement but to attract, provoke, or awaken the interest of individual readers. The individuals touched by Cavell may still find themselves incomprehensible and isolated in their immediate institutional surroundings, yet they have found in Cavell's writing a reprieve from their disillusionment and the stirrings of a new kind of intellectual community — not "the overcoming of [their] isolation, but the sharing of that isolation." 15 For these readers, Cavell has filled the role that moral perfectionism assigns the friend, or someone "whose conviction in one's moral intelligibility draws one to discover it, to find words and deeds in which to express it, in which to enter the conversation of justice" (CHU, p. xxxii).

Cavell decides to stay rather than withdraw; in choosing to stay, he accepts his membership in an admittedly flawed institution. With that membership, however, comes many responsibilities, among them taking an interest in what happens to you and others; being sociable (as opposed to disengaged); participating; staying open to personal change and self-criticism; listening; remaining endlessly responsive to difference; engaging in meet and happy conversations with those around us (adapting Milton, Cavell notes that "a certain happiness, anyway a certain spirited and orderly participation, is owed to the commonwealth by those who have sworn allegiance to it" [CHU, p. 105]). In stressing these responsibilities, Cavell is reaffirming that "I owe to my society a meet and cheerful exchange to reaffirm my consent, or a else a willingness to articulate the public causes of my unhappiness. That there is no measurable limit to my responsibility for the way things are, or to how far the effect of my unhappiness mars the possibility of the general happiness, hence brings into question the fact of our communal existence" ( $C W$, p. 68) - brings it into question by suggesting that it leaves someone out. "Meet and cheerful" here mean not "bubbly and happy"-remember, we have wiped off the fake smile of conformity-but "spirited," which in turn means engaging in exchanges rather than diatribes or one-sided attacks, exchanges where we seek to learn as well as demonstrate something. 
Just as Cavell is not retreating in silent melancholy within or outside the university, neither is he declaring immediate or even eventual victory. There is no guarantee that things will get any better: hence the need for ceaseless responsiveness and "eternal vigilance" ( $C H U$, p. 125). Following Emerson, Cavell is continually counseling patience, persistence, waiting, resourcefulness, improvisation, hope, in the face of discouraging odds and the inevitability of disappointment. He is asking us to conduct our work with "an attitude to our pursuits that is precisely unimposable and unrewardable" (CHU, p. 10): unimposable, because it cannot be forced on ourselves or on others but has to come from within each of us; unrewardable, because it finds fulfillment in every step of the way, not in some ultimate pay off or triumph that may never materialize.

The uncertainty of success returns me to what I earlier called the limits of teaching, or those moments when, as Wittgenstein describes them, justifications come to an end and "my spade is turned." At these times, I feel I have done everything, or at least enough, to make myself clear. Adding to what I have already said is not getting me anywhere-in advancing my own understanding, in spurring on my apparently stalled students. It is time now for my students to respond, not just to regurgitate what they have heard but to go on with it, on their own, maybe in a direction that I cannot anticipate. These are the anxious moments that the remaking of education along corporate lines seeks to minimize by limiting instruction to the most manageable tasks and installing mechanical check points along the way, such as annual standardized tests in American high schools, which sustain the illusion of lock step progress from level to level.

Cavell, by contrast, does not evade the unpredictability of teaching but values it. Again, in the scene of instruction depicted by Wittgenstein, after I have said everything I can, "Then I am inclined to say: 'This is simply what I do." Commentators like Saul Kripke have treated "this is simply what I do" as resolving the teacher's dilemma along the lines of saying to the student, "take it or leave it," or, as Cavell paraphrases Kripke's reading, "after I have done everything to guide you, I am licensed to say, 'do it my way or suffer the consequences,"” with "licensed" carrying the full weight of institutional authority. Cavell, however, takes "this is simply what I do" as something that the teacher is only inclined to say, maybe in the authoritarian, frustrated tone heard by Kripke but maybe in a more passive or personal way: a teacher confessing what he or she does without invoking any institutional authority, admitting to the student "II cannot see here where or how to make myself plainer, but here I am, 
doing what I do, whenever you find you are interested again" (PDAT, p. 204). Waiting like this, giving the student time, means accepting the right of others to contest what I say, to teach me. It means "letting my confidence be challenged, anyway become hesitant in, thoughtful about, expressing itself" (CHU, p. 76), not assuming or mandating concurrence but asking myself "how important it is that we agree, and how thoroughly, in various strains of our form or forms of life, and where we may, or can, or ought to, or must, tolerate differences, even perhaps be drawn to change our lives-or suffer the consequences" (PDAT, p. 204).

What some academic philosophers regard as the most annoying features of Cavell's writing turn out to exemplify the pedagogical values I have been describing. The confidence "hesitant in, thoughtful about, expressing itself" informs seemingly endless sentences that circle back on themselves, qualifying their key points and setting in motion possible further revision. Acknowledging that "this is simply what I do" amplifies Cavell's personal voice in his writing, by which I mean his references to his own earlier work, his promissory notes to himself on topics that one day he hopes to pursue, and his careful tracking of where he stands and how he feels ("I come back to earth," "I feel like saying," and so on). Inviting readers to continue his thinking leads to essays that often end in open-ended questions or in provisional statements that function more as gathering places than as final destinations, as if he is not only summing up what he has said but encouraging further work on the part of the reader. The overall point of the essay admittedly may seem vague, though only when measured against calls for specific actions that Cavell neither precludes nor issues.

I am not suggesting that all teaching and writing must all the time be this tentative and exploratory. Patience has its limits, as does anger. Much as we can move too fast, we can wait too long in reaching conclusions, making decisions, and taking a stand. My point is that the scene of instruction described by Cavell captures a possibility that universities ought to treasure rather than steamroll away in the name of narrowly defined efficiency and productivity. The humility represented in this scene validates the university as place where coercion gives way to consent, judgments can be contested as well as made, and students and teachers can take their time, exchange places, reconsider where they are headed, and remain open to change, in themselves and in others.

Staying in the university, continuing to teach and write, despite all the discouragements that come one's way, all the problems one feels somehow responsible for but cannot solve, thus does mean granting 
some legitimacy to the university. It means ratifying universities as places that remain, if not perfect, at least open to reform, conducive to aversive conversations, places where "happiness and liberty can be pursued and, to whatever extent such a thing is possible, preserved" ( $C W$, p. 75). As Cavell observes, in one of his most explicit statements of support for the university and the academic freedom it should stand for, "I do not have to claim that everything is possible in every period in order to plead this much for universities: that while they may suffer every failing of the institutions of which they partake, they are unique among institutions in preserving the thought that nothing is the only game in town, or that if something is, then there are habitations outside the town where it is not. For that reason, before any other, they have, as they stand, if not my devotion, my loyalty" ( $P H$, p. 274). Devotion here would imply uncritical allegiance; loyalty can, and sometime should, take the form of loyal opposition.

For some critics, I would imagine that claiming even this much for the openness of universities is conceding too much or settling for too little. The unhappiness of these individuals has reached a point where they feel diminished by continuing to stay or participate. In institutions like universities that depend so heavily on consent and engagement, it must always be an open question, subject to collective discussion and personal judgment, whether the evasions, injustices, and exclusions of universities have gone so far as to discredit them altogether. I do not feel that way, at least not now, however much those of us who have decided to stay must remain open to letting our confidence be tested. In any case, to paraphrase a comment by Cavell on Wittgenstein, this much seems to me true: imagine a university without Cavell's writing and the voices he has encouraged. It is a place where our danger to one another grows faster than our help for one another. ${ }^{16}$

Trinity University

1. Stanley Cavell, Themes Out of School: Effects and Causes (San Francisco: North Point Press, 1984), p. 31. Cited in text as TS.

2. Stanley Cavell, Cities of Words: Pedagogical Letters on a Register of the Moral Life (Cambridge: Harvard University Press, 2004), p. 235. Cited in text as $C W$. 
3. See Stanley Cavell, Must We Mean What We Say?: "It is hardly an accident that creative scientists are on the whole at home in a university and that creative artists on the whole are not." (1969; rpt. Cambridge: Cambridge University Press 1976), p. xxvii.

4. Quoted in David L. Kirp, Shakespeare, Einstein, and the Bottom Line: The Marketing of Higher Education (Cambridge: Harvard University Press, 2003), p. 243.

5. Lindsay Waters, Enemies of Promise: Publishing, Perishing, and the Eclipse of Scholarship (Chicago: Prickly Paradigm Press, 2004), p. 5. Cited in text as EP.

6. Stanley Cavell, Philosophy the Day After Tomorrow (Cambridge: Harvard University Press, 2005), p. 210. Cited in text as PDAT.

7. Stanley Cavell, This New Yet Unapproachable America: Lectures after Emerson after Wittgenstein (Albuquerque: Living Batch Press, 1989), p. 4. Cited in text as NYUA.

8. See Stanley Cavell, Conditions Handsome and Unhandsome: The Constitution of Emersonian Perfectionism (Chicago: University of Chicago Press, 1990), where Cavell takes up, "Why does Emerson care, why ought we to care, whether he is a philosopher?" (p. 60; see also p. 137). Cited in text as CHU. In Cities of Words he also asks, "if we can say that Emerson is a useful, interesting, moving, provocative writer, whose powers increase with increased attention to them, why bother about whether he is called a philosopher or something else, or nothing but a writer?" (p. 21).

9. Quoted in Stanley Cavell, Emerson's Transcendental Etudes, ed. David Justin Hodge (Stanford: Stanford University Press, 2003), p. 146.

10. Cavell says of Wittgenstein's Investigations, "In asking for more than belief it invites discipleship, which runs its own risks of dishonesty and hostility. . . And like Freud's therapy, it wishes to prevent understanding which is unaccompanied by inner change." "The Availability of Wittgenstein's Later Philosophy," Must We Mean What We Say? pp. $71-72$.

11. Stanley Cavell, The Claim of Reason (New York: Oxford University Press, 1979), p. xvi. Cited in text as $C R$.

12. Stanley Cavell, "Film in the University," Pursuits of Happiness (Cambridge: Harvard University Press, 1981), p. 265. Cited in text as $P H$.

13. Ralph Waldo Emerson, “The American Scholar,” Selected Essays, ed. Larzer Ziff (New York: Penguin Books, 1982), pp. 95-96.

14. See Cavell's acknowledgments to Must We Mean What We Say? p. xiii.

15. I adapt here a comment by Cavell on modern art: "It promises us, not the re-assembly of community, but personal relationship unsponsored by that community; not the overcoming of our isolation, but the sharing of that isolation-not to save the world out of love, but to save love for the world, until it is responsive again." "A Matter of Meaning It," Must We Mean What We Say? p. 229.

16. Here is the complete statement that I am paraphrasing: "What is true is: In the culture depicted in the Investigations we are all teachers and all students-talkers, hearers, overhearers, hearsayers, believers, explainers; we learn and teach incessantly, 
indiscriminately; we are all elders and all children, wanting a hearing, for our injustices, for our justices. Now imagine a world in which the voices of the interlocutors of the Investigations continue on, but in which there is no Wittgensteinian voice as their other. It a world in which our danger to one another grows fasters than our help for one another" (NYUA, p. 75). The kind of university that I have been affirming resembles the culture described here. 